\title{
Preparedness of future English teachers as a prerequisite of their professional well-being
}

ISSN 2657-9774; https://doi.org/10.36534/erlj.2021.02.07

\author{
Elena Kovacikova*, Jana Hartanska** \\ *Constantine the Philosopher University in Nitra, Slovakia; ekovacikova@ukf.sk \\ **Constantine the Philosopher University in Nitra, Slovakia; jhartanska@ukf.sk
}

\begin{abstract}
Qualified English teachers in Slovakia need to earn a master degree in teaching. Their university study in bachelor and master years contain theoretical courses in English linguistics, culture, literature, and English teaching methodology accompanied with compulsory teaching practice. Practicum or teaching practice performed at local training schools are supervised by teacher trainers who cooperate with university methodology teachers. The preparedness of university graduates for their real professions has been recently questioned and criticized by educational authorities and public blaming insufficient or prevailing theoretical university preparation. This paper sheds light on the teaching practice of the future English teachers in Slovakia in order to establish their professional well-being. In particular, it discusses the views of the English teacher trainers collected from interviews on the preparedness of university students (pre-service English teachers) for their teaching professions. The qualitative type of the research, a case study with participants - the interviewed teacher trainers on performance of university students was carried out in 2019. The results displayed in a SWOT analysis reveal the gaps that are to be filled by the university preparation. Moreover, the interpretations are based on the linguistic, intercultural and methodological aspects of preparedness that can mirror the challenges in the university preparation of future English teachers in Slovakia. The results and interpretations might contribute towards building professional well-being within European standards of English teachers and their university preparation and the balance between theory and practice.
\end{abstract}

Key words: English teacher university preparation, teaching practice, practicum, case study

\section{Introduction}

Professional terms such as teaching practice and practicum are used in scientific papers interchangeably. Language teacher preparation is holistically discussed in the European Profile for Language Teacher Education - A Frame of Reference ${ }^{11}$ (Kelly et al. 2004) as an outcome of case studies with articulated 40 principles of a quality language teacher preparation. It presents results of a study carried out at 11 European educational institutions that provide language teacher training programs. This Profile has been taken as a model document for measuring the preparedness of future English language teachers in Slovakia. The principles of the quality language teacher education can be divided according to the development of certain competences that are necessary for language teaching career: linguistic, intercultural, and methodological (Kovacikova \& Pechociak 2021).

The topic of the pre-service teachers in connection with their teaching practice has been a focus of the studies carried out by Johnson $(2006,2009)$ focusing on understanding and clarifying the ways they teach. Also, Kabilan and Izzaham (2008) worked with Malaysian pre-service English teachers that reflected on their challenges related to the use of their mother tongue, teacher centered approach and mix-ability teaching. Gang's (2013) study talks about the difficulties of the pre-service English teachers

\footnotetext{
${ }^{11}$ European Profile for Language Teacher Education - A Frame of Reference (2004). Final Report to the European Commission Directorate General for Education and Culture.
} 
to experiment with pedagogical practices that they had learnt during their methodological courses at the faculty. The study from Turkey carried out by Mutlu (2015: 42) searched for the challenges during the practicum in order to find the challenges. The aim was to look for the improvements that can be applied in further teacher preparation. Focus group interviews with the teacher trainers and pre-service teachers were conducted. All the pre-service teachers agreed that teaching practice provided them "effective understanding of the real teaching".

Another recent Turkish study on the pre-service English teachers' practicum expectations and attainments carried out by Ulum (2020) aimed at finding what pre-service teachers expect form the practicum process and what they attain. After reviewing the papers discussing practicum of English teachers the results show that there are only a limited number of studies dealing with its quality and effectiveness.

\section{Methodology and research design}

The qualitative research in a form of a case study, described in this paper is a partial research of the bigger picture of English language teacher education in Slovakia, especially at the Faculty of Education, Constantine the Philosopher University in Nitra. For the purposes of this case study 7 teacher trainers (5 from secondary schools and 2 from elementary schools) were interviewed in order to find out the level of preparedness of the pre-service teachers in linguistic, intercultural and methodological aspects. The interviews were carried out from January 2019 until January 2020. All teacher trainers employed in this research are fully qualified English teachers with more than 5 years of teaching practice who train the university students in their master degree. The task of a teacher trainer is to guide pre-service teachers in pedagogical reality, explain administration, teaching process, evaluation and legal regulations applied in elementary and secondary schools. The tasks of a pre-service teacher are to get acquainted with learners, teaching materials, content, forms and methods applied in teaching. Before being involved in teaching it is common to observe a teacher trainer in order to get an idea how to plan, conduct and evaluate the teaching process. Then, the teacher trainer checks the lesson plan before the teaching happens, observes the teaching process of a pre-service teacher, and gives critical and constructive comments on a teaching performance. In the end of the practicum, the teacher trainer writes evaluation on a trainee based on the previous observation of a teaching process. The researcher was also an interviewer in this qualitative research. Her position at the university is to lead ELT methodology courses in bachelor and master levels and she is also responsible for the practicum at training schools and communication with teacher trainers. Therefore, she is acquainted with teacher trainees as university students carrying out the practicum and teacher trainers who supervise them in the training facilities. Thus, the motivation to find out the opportunities and challenges in order to enhance the professional well-being of future graduates is high.

\section{Data collection}

The data collected from evaluations and interviews were processed qualitatively, categorized into SWOT analyses and interpreted afterwards. The methods chosen for data collection were semistructured interviews with teacher trainers and self-reflections written by the pre-service teachers grounded in the research methodology by Cohen (2007) following also ethical principles. All the research subjects were primarily informed and asked about their willingness to participate in the research, with their right to be withdrawn any time during the research. At the same time, the names of the participants were not publicized and thus, they remained anonymous. The data were collected from January 2018 until December 2019. The answers provided orally (by teacher trainers) or in writing (in evaluations) were further categorized in the three categories:

- Linguistic (concerning foreign language competence of the pre-service teachers), 
- Intercultural (intercultural competence of the pre-service teachers),

- Methodological (classroom management, lesson planning, instruction, discipline, use of mother tongue, evaluation, managing, SEN learners, etc.).

The fourth category of answers consisted of the answers that did not fit in any of the previously mentioned categories. Thus, it is labelled in the SWOT analysis as not applicable N/A.

The semi-structured interviews were carried out with 7 teacher trainers as the available sample. Interviews were conducted in a mother tongue in order to enhance authenticity and natural flow of thoughts and speech. The questions were focused on the following categories:

1. What was a linguistic performance of the pre-service teachers (aim at fluency, accuracy, level of vocabulary adjusted to the level of learners, the mistakes or errors, etc.) - a linguistic category (L)

2. What was their methodological/didactic preparedness? (logical sequencing of activities, variety of forms of work, clear instructions, demonstrations, solving unpredictable situations, classroom management, time management, didactic approaches in teaching vocabulary, grammar, pronunciation or development of language skills, relevant use of mother tongue) - a methodological category (M)

3. What was their intercultural competence? (socio-cultural knowledge (day to day living, history, values, beliefs, taboos), intercultural awareness, intercultural skills (to see contrast between own and target cultures, ability to overcome stereotypes, cultural differences), attitudes, values, sociolinguistic competences, pragmatic competences, non-verbal communication, presenting cultural values, differences, by explanation or actions such as small talk, polite phrases, explanations of intercultural specific situations or events) -an intercultural category (I)

4. Are there any other relevant comments focusing on performances of the pre-service teachers during their teaching practice that are not covered by items $1-3$ ? (n/a)

\section{Findings}

The answers from the interviews were coded, analyzed and summarized in the following SWOT analysis. In order to validate the results the peer-debriefing technique was used. Thus the trustworthiness of the findings was assured when the answers were categorized into the strong, weak qualities, opportunities or threats.

Table 1: SWOT analysis

\begin{tabular}{|c|c|}
\hline $\begin{array}{l}\qquad \text { Strengths } \\
\text { Enthusiasm }(N / A) \text {, } \\
\text { New activities }(M) \text {, } \\
\text { Authentic materials }(I, M) \text {, } \\
\text { English language competence }(L) \text {, } \\
\text { Clear instructions }(M, L) \text {, } \\
\text { Interesting interactive materials }(M) \\
\text { Positive approach towards students }(M, L) \text {, } \\
\text { Friendly approach }(n / \text { / }) \text {, } \\
\text { Appealing warm-ups }(M) \text {, } \\
\text { Small talk (I), } \\
\text { First name addressing }(M) \text {, } \\
\text { Positive classroom rapport }(M) \text {. }\end{array}$ & $\begin{array}{l}\quad \text { Weaknesses } \\
\\
\text { Weak language competence }(L) \text {, } \\
\text { basic grammar mistakes }(L) \\
\text { No small talk }(I) \text {, } \\
\text { little personal involvement }(M) \text {, } \\
\text { bad time-management }(M) \text {, } \\
\text { SEN learners }(M) \text {, } \\
\text { little feedback }(M, L) \text {, } \\
\text { stress, anxiety }(\mathrm{n} / \mathrm{a}) \text {, } \\
\text { teacher centeredness }(M) \text {, } \\
\text { constant use of the textbook }(M, L) \text {, } \\
\text { less sensitive error correction }(M, L) \text {. }\end{array}$ \\
\hline $\begin{array}{l}\quad \text { Opportunities } \\
\text { More flexibility }(L, M) \text {, } \\
\text { Smaller dependence on textbooks }(L . M) \text {, } \\
\text { More linguistic control in instructions }(L) \text {, } \\
\text { Less self-control in explanations }(n / a) \text {, } \\
\text { More student centeredness }(M) \text {, } \\
\text { Personalization of the content }(M, I) \text {, } \\
\text { Use of learning opportunities }(M) \text {, } \\
\text { Building linguistic and professional } \\
\text { self-confidence }(L, M) \text {, } \\
\text { Effective work with SEN learners }(M) \text {, } \\
\text { Less direct use of language when correcting } \\
\text { students }(L, M) \text {, } \\
\text { More intercultural personal involvement }(I) \text {. }\end{array}$ & $\begin{array}{l}\text { Lots of grammar mistakes }(L) \text {, } \\
\text { No smile }(n / a) \text {, } \\
\text { Impolite behavior towards teacher trainers, } \\
\text { students }(n / a) \text {, } \\
\text { Lack of pair and group work }(M) \text {, } \\
\text { Complicated instructions }(M, L) \text {. } \\
\text { Inefficient use of mother tongue }(M, L) \text {. }\end{array}$ \\
\hline
\end{tabular}




\section{Results and interpretations}

The results shown in the SWOT analysis above in the text are taken from the responses of the teacher trainers, 5 from secondary schools and 2 from elementary schools who trained pre-service teachers. The common procedure is to have 3-5 pre-service teachers within one teaching practice (i.e., for two weeks) and the interview was carried out immediately after the teaching practice was finished. They were also asked to provide an authentic example from the teaching practice if they could recall any in order to enhance more precise categorization. Also, the precise number representing an item in SWOT analysis is not available as the teacher trainers had their notes and comments mainly on a group of students. The results attempted to give an overall perception on inquired issues focusing on preparedness of the pre-service teachers for their teaching profession. The answers were divided into the linguistic, intercultural and methodological categories.

As for the linguistic competence, most of the pre-service teachers were evaluated as good, very good and excellent in their language proficiency, however, three teacher trainers complained that there is always one or two pre-service teachers in a group who make basic mistakes in grammar, mix a word order mainly in questions, do not have enough vocabulary and thus their linguistic competence is poorer. These facts were mostly observed in a bilingual section (English-Slovak) of a secondary grammar school where the discrepancy between the foreign language proficiency of learners and pre-service teachers was more than obvious. A bilingual secondary school in Nitra belongs to training schools for pre-service English language teachers. Thus, pre-service teachers during their teaching practice in winter semesters teach bilingual students - teenagers who are enrolled according to their English language level from the whole country. Therefore, their language competences are very high when they start studying at the secondary school. As stated by Daszkiewicz et al. (2018: 23) "a constant necessity to consider and choose wisely between the correctness and fluency" brings uncertainties in performances of teacher trainees who control their speech production and sometimes it results unreasonably in less confident outcomes. Most of the pre-service teachers who realize their teaching practice are stressed from not being linguistically competent because sometimes it is their first time teaching real students and mostly, they are surprised with students' high level of English. What is more worrying is the fact that more than a third of the pre-service teachers are likely to feel anxious and stressed when teaching students, especially in this bilingual section. On the contrary, they feel more confident linguistically in teaching at elementary schools and their linguistic performance is more self-assured. These findings open the space for working with foreign language anxiety during university preparation of future teachers (Cf. Král'ová, 2016).

The methodological category revealed that some students strictly follow the textbook as they do not feel safe to try some other additional activities. At the same time, time management as a typical drawback of novice teachers was observed. Language lessons are about language production and the most effective techniques for producing the language with all the students at the same time can be enhanced through pair or group work. There were two complaints of not using any other forms of work apart from a teacher and classroom. The ineffective use of mother tongue especially with those preservice teachers who do not feel confident enough in English was also observed. Another evidently initial negative was seen in insufficient direction towards learners stemming out of the extreme selfcontrol (personal and linguistic). Thus, in one specific case, a pre-service teacher who is normally very sociable and open-minded acted during her teaching as if she never smiled. On the contrary, pre-service teachers were positively evaluated for building positive rapport, friendly approach to the students, bringing authentic materials to the classroom, addressing students with their first names, supporting and positively approaching their learners.

Intercultural competence covered involvement of culturally bound situations in conversations, such as small talk, politeness, addressing, and if applicable also comparisons when teaching particular topics 
such as festivals, housing, food, clothing, school, etc. Mostly, pre-service teachers were praised for introductory small talk when they started teaching as well as for being polite. There were only two teachers who mentioned three students that used very direct language, did not explain the story behind the festivals such as Thanksgiving and skipped the small talk before checking homework. The use of the authentic material is in this case categorized in intercultural field, as it was mainly bound to the sample from the TV series, advertisements connected to the topic they were teaching. This use was directly asking for comparison or explanation of cultural differences.

SWOT analysis is divided into four categories. On the one hand, strengths summarize the positive aspects that were gathered from all the interviews with teacher trainers. Weaknesses, on the other hand, were commented as negative aspects in teaching performances of the pre-service teachers. The categories named threats and opportunities are from the point of view of improvements seen as the most important ones. Threats cover critical comments such as being late for the lesson, not behaving polite towards teacher trainers or students (alleged mocking the students, arguing with a teacher trainer).

The opportunities that were articulated out of all the interviews summarized in the SWOT analysis suggest possible improvements that could be implemented in further preparation. From the linguistic point of view, it is more than necessary to build and develop linguistic competences and boost the confidence in expression and correct and precise spoken production in English. Reid (2014: 122) comments on the intercultural competences of the English teachers pointing out that they cannot identify intercultural competences and thus they 'include socio-cultural knowledge (visible parts of the cultural iceberg) in their lessons and the invisible aspects (sociolinguistic, pragmatic and paralinguistic) they neglect or do not realize their importance. From the intercultural point of view, small talk that was praised in some of the pre-service teachers, lacked in the others as well as not enough contextualized tasks when the cultural issues were discussed. Some of the pre-service teachers do not have enough personalized intercultural experience and therefore they are not able to transfer them to the learners. They use very direct language mainly when correcting the learners that is probably Slovak interference, i.e., no please, thank you, could you, would you, etc. From the methodological point of view, the preservice teachers should improve in redirecting their focus from themselves towards students, from a teacher-centered approach towards a learner-centered one. At the same time, following the textbook only without any contextual or personalized connection causes only a shallow coverage of the topic. The pre-service teachers often do not make use of learning "opportunities" that occur in the classroom. As for example, when students are introduced a new tense and one of them 'complains' about the number of tenses that exist in English, a teacher can use the complaint as a motivational moment for discussion and further positive and supportive development. In the unpredictable situations such as failure of technology or lack of time for running the activities, odd number of students during pair work preservice teachers need flexible reactions. SEN learners also represent difficulties for the pre-service teachers who usually know their impairments only from theories.

\section{Conclusion}

This qualitative research was carried out with the aim to find out the level of preparedness of the future English teachers for teaching as a prerequisite for their professional well-being. Through interviewing seven teacher trainers as an available sample, two of them from elementary school and five of them from secondary schools, the data were gathered from the comments on the trainees' performances. Three of them justified their comments also in their evaluations. Four of them did not have evaluations of individual students but the groups of students, so they summarized their comments on the group of students with particular examples. All the data were categorized into the linguistic, intercultural and methodological aspects. Later on, they were analyzed in a SWOT analysis showing the 
strengths, weaknesses, opportunities and threats in the trainees' teaching performances. The aim was to categorize the answers and find out the improvements for more effective preparedness of the preservice education in linguistic, intercultural and methodological categories and these qualitative data were gathered and interpreted. Generally speaking, the findings showed the gaps that can be focused on more in the English language teacher university education particularly in the content of the university linguistic courses that should build up linguistic competences and thus contribute towards professional well-being of future teachers. The research findings highlight the importance of bridging theories and realities in intercultural courses that should develop cultural awareness and teach students how to transfer it to learners. Last but not least, methodological courses should deal with the principles of authentic and effective teaching and learning.

In order to follow objective principles of research conduct it is necessary to mention the limits of this study. The first limitation of this qualitative part is the fact that these data were collected after the first type of teaching practice at secondary school (during the winter term) and elementary school (during the summer term) of the pre-service teachers in their first grade of master degree. In their bachelor degree they had completed their observation practice thus this was their first-time teaching during their pre-service preparation. Lots of their methodological failures could have been caused by their first real experience in teaching at schools. Secondly, some of the negative comments might have been caused by the stress of the trainees and not by the lack of knowledge or other circumstances that can occur in educational realms. All in all, more insights into the quality of the teaching practice in forms of the scientific and professional papers are necessary in order to build up a bigger and more objective picture.

Acknowledgements: The paper was published under the research KEGA 002UKF-4/2020.

\section{References}

Cohen, L., Manion, L., Morrison, K. (2007). Research Methods in Education. Routledge. Available in pdf at https://gtu.ge/Agro-Lib/RESEARCH\%20METHOD\%20COHEN\%20ok.pdf.

Council of Europe (2007). Guide for the Development of Language Policies in Europe. https://rm.coe.int. Council of Europe (2007). European Portfolio for Student Teachers of Languages. A reflection tool for Language Teacher Education. Available at: http://archive.ecml.at/mtp2/fte/pdf/c3_epostl_e.pdf

Daszkiewicz, M., Kusiak, M., Wenzel, R. (2018). Educational Role of Language Skills. Poland: Gdansk University Press

Gadušová, Z., Hartanská, J. (2002). Teaching English in Slovakia - Past, Present and Future. CAUCE Revista de filologia y sididactica, 25: 225-280.

Gan, Z. (2013). Learning to teach English language in the practicum: what challenges do non-native ESL student-teachers face? Australian Journal of Teacher Education, 38(3): 92-108.

Johnson, K.E. (2006). The sociocultural turn and its challenges for second language teacher education. TESOL Quarterly, 40(1), 235-237. https://doi.org/10.2307/40264518.

Johnson, K.E. (2009). Second Language Teacher Education: A sociocultural perspective. New York: Routledge.

Kabilan, M.K., Izzaham, R.I.R. (2008). Challenges faced and the strategies adopted by a Malaysian English language teacher during teacher practice. English Language Teaching, 1(1): 87-95.

Kováčiková, E., Pechočiak, T. (2021). English teacher education in Slovakia. Slavonic Pedagogical Studies Journal, (10). doi: 10.18355/PG.2021.10.2.3.

Kováčiková, E. Prokeinová, R. (2012). Focus Groups in Educational Research, in: S. Pokrivčáková Research in Language Pedagogy (pp. 62-87). Brno: MSD.

Král'ová, Z. (2016). Foreign Language Anxiety. Nitra: UKF. 
Mutlu, G. (2015). Challenges in Practicum: Two Sides of the Coin. International journal of Learning and Teaching, 7(1): 38-48.

Reid, E. (2014). Intercultural aspects in teaching English at primary schools. Frankfurt am Main: Peter Lang Edition.

Ulum, Ö. G. (2020). Pre-service English Teachers' Practicum Expectations and Attainments. Turkish studies - Education, 15(2): 1287-1297, available at: https//dx.doi.org/10.29228/TurkishStudies.41629. 